\title{
The Team Process: Insights from the LEAD Experience
}

\section{Vincent Bagire, Makerere University, Uganda Betty Jane Punnett, University of the West Indies, Cave Hill Campus, Barbados}

\section{Introduction}

Globalization in the business world, combined with technological developments, has resulted in a proliferation of multi-country, virtual teams (Han \& Beyerlein, 2016), and this phenomenon has been increasing, particularly over the past decade (Schille \& Mandviwalla, 2014). This has happened in academia as elsewhere. Technology has made it easier to communicate and collaborate across countries, and working with academics outside the home country has become more common. The Leadership Effectiveness in Africa and the African Diaspora (LEAD) project is an example of a multi-country virtual team academic project. It involves collaborators from seven African, three Caribbean, and three North American countries. The LEAD research project was initiated in 2007. It is diverse at many levels and today has participants who continue to learn and act together. The team's achievements include research and publications and a number of grants to support the research. This paper discusses the factors behind these achievements among a group of diverse participants, including task focus, team composition, individual motivation, and leadership. The paper emphasizes the beginnings of the LEAD team, its growth, leadership, academic achievements, and challenges, and provides insights for other scholars interested in virtual team collaborations. We also include comments from team members that illustrate aspects of the team process. These all elucidate aspects of the factors identified as important to the virtual team success.

The concept and practice of teamwork has become a key to organizations' performance, where the work of any group is a shared responsibility, with shared benefits (Sharma \& Kirkman, 2015). There are several important aspects to successful teamwork: familiarity with and appreciation of each member, understanding the team's objectives, goals, and tasks, clarity about the time available for working together, and the resources available. In addition, Kayworth, Leidner and Mora-Tavarez (2002) found that effectiveness in virtual teams was associated with mentoring and empathy, the ability to assert authority, articulating team members' relationships, and regular, detailed, prompt communication. The LEAD project has illustrated the importance of these aspects of teamwork. We would add the use of technology as a critical component.

\section{The Foundations of the LEAD Team}

The LEAD project began as an individual effort, but it has evolved into a great team. Initially, one of the authors was interested in the apparent cultural and behavioral links between the Caribbean and both Africa and European colonial powers (Punnett, Singh, \& Williams, 1994) and designed a research project to look at these relationships from a management perspective. Over time, this became the LEAD project. For the project to be viable, it was clear from its inception that it would need input from many people in many countries. A critical element therefore was the search for collaborators in a variety of countries. Collaborators were identified through a variety of networking activities. Personal contacts were used, and the project outlined to them. This resulted in a small group of participants who recruited other researchers from their colleagues, essentially the equivalent of a snowball sampling technique. This process relates to the idea that familiarity with team members is a component of success. This is difficult to achieve in a virtual situation, but our approach meant that team members were known to at least some other team members. Another advantage of this approach is that collaborators joined the team because they wanted to be part of the project and were interested in the research topic; thus, from the beginning they were aware of the project's objectives, and accepted these.

The informal nature of the team formation process has meant, however, that team members might have quite varied personal objectives and expectations. There are also different institutional priorities which contribute to individual priorities. To deal with this, the early team members developed a detailed protocol, identifying levels of team membership and responsibilities 
associated with membership. The protocol agreement, which each team member signed, included team structure, data ownership and outputs, acknowledgements, ethics, publication rights, and so on. We believe this is a vital aspect for managing a virtual team, collaborating from different parts of the world. The potential for varying values, goals and so on, requires a clear statement of expectations, responsibilities and authority.

\section{The Team Makeup}

The early project leaders have a special interest in Africa but were not based in Africa. They can be termed "outsiders" in the African context. This made the makeup of the rest of the team especially critical, as other team members had to provide the "insider" African perspective. There is substantial variance among team members in terms of gender (both male and female), age (ranging from early 20s to 70), academic levels (from masters degrees, through new PhDs, to Professor emerita), career stage (from junior faculty through mid-career to late career retired scholars), and regional dispersion (13 countries, different continents). This diversity has actually facilitated the cohesion in the team. Cohen and Bailey (1997) proposed a heuristic framework for team effectiveness which included diversity. In our experience, diversity works because team members are conscious of the diversity and seek to accommodate it in their interactions. One team member commented "I enjoy participating because the project is so relevant, and I enjoy working with people from so many countries ... but sometimes I feel it is so big that I have difficulty grasping the totality of the results."

The LEAD team process has been both virtual and physical. The team maintains a group mail account for sharing information. The group holds meetings at given intervals by Skype, and physically, when possible, during academic meetings. However, the entire team has never met, and some members do not know each other by face, even though they have communicated and worked together. Virtual platforms provide a means to share and synthesize information, discuss differences, and make decisions. It is clear that technology has made this team process substantially possible.

The team was initially structured with a core team, and partners, with the former responsible for team interactions and all major directional decisions. The core team would sanction publications and be included as co-authors on works arising from the project. Other members would take on projects with a good deal of autonomy and be responsible for data gathered in their country jurisdictions. We believed it was critical, because of the virtual nature of the team, that there be some central authority and decision making, particularly relating to carrying out data collection and analysis, and publication of findings.
We wanted the project to meet the highest scholarly standards, and this central authority allowed a degree of control. These are critical to performance and satisfaction.

The written protocol provided a basis for team members to identify psychologically with the team's values and has worked well to ensure the team's success. Not surprisingly, however, changes have occurred over time because of external events as well as internal group dynamics. Members have left the team, sometimes formally, and sometimes silently. Newer members have joined and some may be unaware that there is a requirement to sign a protocol and its detailed provisions. The team is currently addressing this issue, by bringing it to all members' attention.

Leadership of the team has been key to its longevity as well as for dealing with challenges. Original members have contributed to the growth of the team by raising funds, supporting team members with cash subsidies for travel (especially relevant for members from Africa who have little funding), initiating meetings and research tasks, encouraging communication, and driving the overall team process. One team member

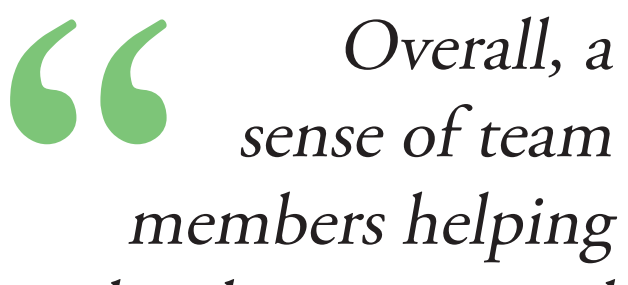
each other to succeed has been a core value that has contributed to the team's success. notes that "they relay strong, unequivocal reminders about tasks and deadlines, and threaten reprimands for non-compliance, but as well they always appreciate individual and group achievements." Team motivation is anchored on three key factors - task clarity, member composition, and the team process. In the LEAD team, tasks are clearly spelt out and usually voluntarily assigned, contribution from all members is expected, and members provide support and peer reviews for others. This enhances learning, developing a common vision and a rational use of resources. Data storage and analysis was also centralized with one team member responsible for the data. This has been invaluable in keeping the data well organized, and available to all. Overall, a sense of team members helping each other to succeed has been a core value that has contributed to the team's success.

One team member noted that "a sense of community, mentorship, mutual respect, focus on goals and collective responsibility has been the hallmark of the LEAD team. The core team members continue to maintain sharp focus on the 
research outcomes while cascading the objectives to regional team members who then work closely with other scholars in data collection and analysis." Another commented that "workshops, conferences and symposia have served as important avenues for capacity building. Clear communication and updates from the core team contributed to success. The team has benefited from reference materials that have been made available by team members both at the core and regional levels. Sharing announcements of conferences and calls for papers has been a great motivator." Additionally, "the pairing of core members with regional members in co-authorship continues to build capacity of the team members who would not be able to easily author on their own."

\section{Achievements}

We can learn from the team's achievements. First, it seems important to create a "brand" for the team. The LEAD acronym is essentially this brand, and the team has worked to ensure that the brand is recognized across the scholarly management community. This allows team members to easily communicate their membership in the team. Other teams, such as the GLOBE team, have also benefitted from this approach. Achievements are also important to team cohesion and productivity, because team members can see the clear evidence of their contribution to the project. The team has completed empirical research, and developed an instrument to measure leadership; together and individually, members have published and edited books and chapters, journal articles, and a special issue. The team has also presented papers and hosted symposia and workshops during academic meetings. All of these activities have contributed to the sense that collaboration has tangible benefits.

Interactions which are not directly scholarly also contribute substantially to the team's ability to continue working successfully together. The team has held meetings both online and physically, exchanged email, attended dinners and lunches together, and engaged in team building exercises, including a national park drive in Tanzania. These activities are relevant because when team members get to know each other personally, they then feel more responsible for ensuring the success of others, and thus of the team.

\section{Challenges}

While LEAD can identify achievements, there have also been challenges. One major challenge has been financial constraints that have affected individual involvement, as members often cannot make it to conferences to present papers and attend joint activities. Members' busy schedules at their respective institutions have made it impossible for some members to keep pace, or even to respond to the group mail information as and when expected. Culturally, there are also differences in work methods that have surfaced; members from the West tend to have a monochromic approach to work and time management, while Africans are polychromic at work and can seem disorganized and uncommitted to their western counterparts. Combined with a lack of good facilities in African universities, this militates against the commitment of members to get group tasks achieved in a timely and quality manner.

In addition, younger members of the team have substantial academic and non-academic responsibilities and time allotted to LEAD tasks may not be equal. This can sometimes lead to animosity and conflict. It may be that the objectives and deadlines seem somewhat arbitrary to some team members, and therefore they do not fully accept them, even though they virtually "agree" to them. Taras et al. (2016) reported from a study of an international student collaboration project that up to seventeen percent of participants can be what they term "free-riders," and it may be that our team is experiencing this - a certain number of participants who want to be part of the team, but do not want to perform the work required of participants (of course, Taras' sample was students, whereas LEAD is made up of researchers). Taras et al. found that the threat of exclusion from the team (and actual exclusion in a small number of cases) was an effective counter to free riding. A challenge for all virtual teams is eliminating non-productive members and ensuring

\begin{tabular}{|c|c|c|}
\hline Opportunities & Challenges & Best Practices \\
\hline $\begin{array}{l}\text { - Joint publications } \\
\text { - } \quad \text { Multi country collaboration } \\
\text { - } \quad \text { Access to grants } \\
\text { - Mentorship advantages } \\
\text { - Global collaborations } \\
\text { - Joint projects like Special issues, } \\
\text { - Book chapters, articles, conference papers } \\
\text { - Creating a research brand }\end{array}$ & $\begin{array}{ll}\text { - } & \text { Basic cultural and other } \\
& \text { differences among members } \\
\text { - } & \text { Unequal access to information } \\
\text { - } & \text { Poor facilities in African setting } \\
\text { - } & \text { Differences in institutional priorities } \\
\text { - } & \text { Busy academic schedules } \\
\text { - } & \text { Differences in work ethics } \\
\text { - } & \text { Free riders } \\
\text { - } & \text { Perceived inequality in benefits } \\
\text { - } & \text { Time differences }\end{array}$ & $\begin{array}{l}\text { - } \quad \text { Strong leadership } \\
\text { - } \quad \text { Binding protocol } \\
\text { - } \quad \text { Centrality of direction } \\
\text { - } \\
\text { - } \quad \text { Eultiple projects } \\
\text { - } \quad \text { Technole share of direct benefital linkages } \\
\text { - } \quad \text { Person to person contact } \\
\text { - } \quad \text { Clear member recruitment } \\
\text { - } \quad \text { Team building }\end{array}$ \\
\hline
\end{tabular}


that newcomers are well integrated. This is a particular issue in terms of the core team members because of the vital role that they play in the overall process. The LEAD team is continuing to work out these processes.

\section{The Way Forward}

The framework for this paper was developed at a meeting of the LEAD team, with eight members present in Tanzania and others on Skype. In addition, two book chapters, two conference papers, and two journal papers were planned and timelines agreed on. The team also agreed to develop training materials based on the research. The next meeting of the group was fixed. These decisions exemplify the cohesive process that has led to the success of the team. Clear goals and tasks, shared decision making and responsibility, a core retaining final authority and control, expectations of tangible outputs, and continued strong leadership. The team will work hard in the next months, team leaders will circulate materials and reminders for deadlines, each member will peer review all the papers before final submissions. At the same time members will exchange ideas on expanding and developing the project. There are high expectations for the team, but challenges will also persist. In the next steps the group will identify more partners and collaborators from within Africa and the diaspora and this will add to the challenges. It will be important to return to the protocols, review them, and ensure that all members sign on. Continuity is a particular issue at this point. Initially, the structure and processes were relatively informal, and members joined because of personal interests. As the project has grown and continues to develop, it may be necessary to formalize much of this, so that leaders and the core can change as needed. Overall, the team process, along with others such as GLOBE, may provide the subject for a research project to understand better the specifics of these teams, and what works best for virtual academic teams. To summarize the practical and theoretical implications, the previous table points out the opportunities, challenges and best practices from the LEAD insights on virtual team processes. country. International Journal of Intercultural Relations, 18(1): 99-115.

Schiller, S. Z., \& Mandviwalla, M. 2014. Virtual team research: An analysis of theory use and a framework for theory appropriation. Journal of Management, 41 (5): 1313-1337.

Sharma, P. N., \& Kirkman, B. L. 2015. Leveraging leaders: A literature review and future lines of inquiry for empowering leadership research. Group and Organization Management, 40(2): 193-237.

Taras, V., Tullar, W., Steel, P., O’Neil, T., \& McLarnon, M. 2016. Free-riding in global virtual teams: An experimental study of antecedents and strategies to minimize the problem. Paper presented at the Academy of International Business annual conference, New Orleans, LA, June 27-30, 2016.

Vincent Bagire (vbagire@mubs.ac.ug) Ph.D. University of Nairobi, Associate Professor, Makerere University Business School, 20 years lecturing Management. Research interests theory and practice Strategic/General Management in African business, public and civil society organizations; current research Managerial Roles in Uganda. Member AOM, AFAM - former Global Representative for Africa and current member, Research committee (BPS division). Community interest support to local families in improving education standards.

Betty Jane Punnett (eureka@caribsurf.com) holds a Ph.D., New York University and is Professor Emerita, University of the West Indies (Cave Hill). Research on the impact of culture on management, particularly the Caribbean. Published extensively in international journals, books and encyclopedias. Recently authored Management: A Developing Country Perspective, co-authored book on leadership in Africa and the African diaspora. An active member of $A O M, A I B$, and AFAM, and founding editor of Insights.

\section{References}

Cohen, S. G., \& Bailey, D. E. 1997. What makes teams work: Group effectiveness research from the shop floor to the executive suit. Journal of Management, 23(2): 239-290.

Han, S. J., \& Beyerlein, M. 2016 . Framing the effects of multinational cultural diversity on virtual team processes. Small Group Research, 47(4): 351-383.

Kayworth, T. R., Leidner, D. E., \& Mora-Tavarez, M. 2002. Leadership effectiveness in global virtual teams. Journal of Management Information Systems, 18(3): 7-40.

Punnett, B. J., Singh, J., \& Williams, G. 1994. The relative influence of economic development and Anglo heritage on expressed values: Empirical evidence from a Caribbean 